\title{
Telemedicine Expands Hydroxyurea Monitoring for Children Living with Sickle Cell Disease in Rural South Georgia
}

\author{
Rebecca Stone ${ }^{1}$, Krystle Stone ${ }^{2}$, Yunmi Chung ${ }^{1}$, Afshin Ameri ${ }^{2}$ and Betty S Pace ${ }^{2 *}$ \\ ${ }^{1}$ Institute of Public and Preventive Health, Augusta University, Augusta, Georgia \\ ${ }^{2}$ Department of Pediatrics, Augusta University, Augusta, Georgia
}

*Corresponding author: Betty S Pace, Department of Pediatrics, Augusta University, Augusta, Georgia

\section{ARTICLE INFO}

Received: 幽 October 09, 2019

Published: 幽October 17, 2019

Citation: Rebecca Stone, Krystle Stone, Yunmi Chung, Afshin Ameri, Betty S Pace. Telemedicine Expands Hydroxyurea Monitoring for Children Living with Sickle Cell Disease in Rural South Georgia. Biomed J Sci \& Tech Res 22(1)-2019. BJSTR. MS.ID.003697.

Abbreviations: SCD: Sickle Cell Disease; HU: Hydroxyurea; CHOG: Children's Hospital of Georgia; GDPH: Georgia Department of Public Health; CMS: Children's Medical Services; IRB: Institutional Review Board; NHLBI: National Heart Lung and Blood Institute

\begin{abstract}
Sickle Cell Disease (SCD) is one of the most common genetic blood disorders in the United States (US) however, patients continue to experience barriers for receiving evidence-based standards of care, particularly those living in medically underserved communities. The purpose of this work was to survey patient satisfaction with subspecialty medical care delivered via telemedicine clinics. The telemedicine coordinator tracked the number of patients scheduled, types of visits and clinic show rates. Surveys completed by SCD patients receiving care in hematology telemedicine clinics held in South Georgia evaluated patient satisfaction and quality improvement efforts. During the observation period, 213 hematology visits occurred mainly for hydroxyurea follow-up and newborn screening confirmation and education. The telemedicine experience of families was overall positive with an average score of $3.79 \pm 0.43$ out of 4 points total, for the ten questions surveyed. A majority of the families $(42.5 \%)$ preferred telemedicine consultation to onsite physician visits $(23.8 \%)$ and $91.3 \%$ of families reported they would use telemedicine again. Patients reported positive experiences with telehealth technology, staff and hematologists and rated telemedicine services favorable. Telemedicine is a feasible approach to enhance access to hematology subspecialty medical care for SCD.
\end{abstract}

Keywords: Sickle Cell Disease; Telemedicine; Hydroxyurea; Rural Medicine

\section{Introduction}

Sickle Cell Disease (SCD) is one of the most common genetic blood disorders in the United States affecting approximately 100,000 people and over 20 million worldwide mainly in low resourced countries [1]. Despite the progress made in medical care, people with SCD continue to experience significant barriers to receiving evidence-based standards of care recommended by the NIH National Heart Lung and Blood Institute [2]. Because of the complexity of clinical symptoms and long-term complications in SCD, approximately $\$ 488$ million is spent in annual medical care costs in the United States (US) creating an unsustainable burden to families and healthcare systems [1]. Furthermore, people living in medically underserved communities experience limited access to a hematologists care. Telehealth technology provides a means to expand medical care and address disparities in access to subspecialty care for children with SCD.

Telehealth uses computer-based technologies to provide healthcare and improve access to medical services for people living in rural communities [3]. Telemedicine was established for SCD at the Medical College of Georgia, Augusta University (AU) in the late 1990s. Woods et al. demonstrated the success of onsite outreach clinics held in South Georgia health departments for the management of SCD [4-6]. When combined with onsite visits, telemedicine clinics increased access to subspecialty care for patients with SCD and decreased travel time for families and physicians, however telemedicine was discontinued. With recent recommendations to offer hydroxyurea to children regardless of 
disease severity and the large number of SCD patients living in South Georgia serviced ty the AU Pediatric Sickle Cell Program, a need to re-establish access to care through telemedicine clinics was identified.

The main approach to improve medical outcomes for people with SCD has been education and scheduled medical follow-up with primary care providers and referral to hematologists to treat complications such as acute vaso-occlusive episodes, acute chest syndrome and stroke among others [7]. Moreover, diagnosis by newborn screening and initiation of penicillin prophylaxis and pneumococcal vaccination impacted survival [8]. Hydroxyurea (HU) was the first FDA-approved drug for the treatment of adults with SCD [9]. However, precise HU dosing to avoid bone marrow toxicity requires frequent clinic visits to monitor blood counts and evaluate liver function. With the completion of the BABYHUG study demonstrating safety and efficacy of HU in young children, [10] the recommendation to offer $\mathrm{HU}$ at 9 months of age 2 increased the demand for subspecialty care to manage therapy. A second challenge of long-term $\mathrm{HU}$ treatment is adherence to medication regimens. To address this issue, Crosby et al. [11] assessed HU adherence in persons 6-21 years old with SCD. Utilization of a webbased tool proved effective to improve adherence for participants reporting transportation as a barrier to adherence. Furthermore, a high patient satisfaction with telehealth approaches $(>90 \%)$ was reported during the study period.

Table 1: Pediatric sickle cell program demographics.

\begin{tabular}{|c|c|c|c|c|c|c|}
\hline & \multicolumn{6}{|c|}{ Outreach Clinic } \\
\hline & Albany & Dublin & Valdosta & Waycross & Augusta & Total \\
\hline & $(N=201)$ & $(N=50)$ & $(\mathrm{N}=112)$ & $(N=40)$ & $(N=306)$ & $(\mathrm{N}=709)$ \\
\hline & N (\%) & N (\%) & N (\%) & N (\%) & N (\%) & N (\%) \\
\hline \multicolumn{7}{|l|}{ Sex } \\
\hline Male & $102(50.7)$ & $29(58.0)$ & $51(45.5)$ & $20(50.0)$ & $186(60.8)$ & $388(54.7)$ \\
\hline Female & 99 (49.3) & $21(42.0)$ & $61(54.5)$ & $20(50.0)$ & $120(39.2)$ & $321(45.3)$ \\
\hline \multicolumn{7}{|l|}{ Race } \\
\hline African American & $201(100.0)$ & $50(100.0)$ & $112(100.0)$ & $40(100.0)$ & 304 (99.3) & 707 (99.7) \\
\hline Hispanic & $0(0.0)$ & $0(0.0)$ & $0(0.0)$ & $0(0.0)$ & $2(0.7)$ & $2(0.3)$ \\
\hline \multicolumn{7}{|l|}{ Hemoglobin Genotype } \\
\hline HbSS & $89(44.3)$ & $34(68.0)$ & $81(72.3)$ & $23(57.5)$ & $199(65.0)$ & $426(60.1)$ \\
\hline $\mathrm{HbS} \beta^{0}$ Thalassemia & $6(3.0)$ & $0(0.0)$ & $1(0.9)$ & $1(2.5)$ & $4(1.3)$ & $12(1.7)$ \\
\hline $\mathrm{HbSC}$ & $42(20.9)$ & $10(20.0)$ & $24(21.4)$ & 7 (17.5) & $71(23.2)$ & $154(21.7)$ \\
\hline $\mathrm{HbS} \beta^{+}$Thalassemia & $13(6.5)$ & $1(2.0)$ & $5(4.5)$ & $5(12.5)$ & $28(9.2)$ & $52(7.3)$ \\
\hline Other SCD & $50(25.4)$ & $5(10.0)$ & $1(0.9)$ & $4(10.0)$ & $4(1.3)$ & $64(9.1)$ \\
\hline \multicolumn{7}{|l|}{ Hydroxyurea } \\
\hline Yes & $34(16.9)$ & $19(38.0)$ & $24(21.4)$ & $13(32.5)$ & $65(21.2)$ & 155 (21.9) \\
\hline No & 167 (83.1) & $31(62.0)$ & 88 (78.6) & 27 (67.5) & 241 (78.8) & 554 (78.1) \\
\hline
\end{tabular}

To compliment onsite visits, telemedicine clinics occur 6-9 times per year in local health departments in South GA. CMS nurses in collaboration with the hematologist establish a monthly schedule
The Pediatric Sickle Cell Program at the Children's Hospital of Georgia (CHOG) provides services for over 700 children living in Augusta and rural South Georgia through on-site outreach clinics located in community health departments. The goal of outreach clinics is to expand access to care for children with SCD living in rural communities where hematologists are not available. To meet the increasing needs for HU therapy and newborn screening confirmatory testing, AU established a telehealth partnership with the Georgia Department of Public Health (GDPH). Since 2017, telemedicine clinics established in South Georgia have greatly enhanced access to subspecialty care for the management of HU therapy and genetic education for hemoglobinopathy carriers identified by newborn screening. Herein, we describe our telemedicine program and patient satisfaction with medical care delivered via telehealth technology.

\section{Materials and Methods}

\section{Clinic Sites and Patient Population}

The AU Pediatric Sickle Cell Program conducts on-site outreach SCD clinics 3-6 times per year depending on patient population, in four South Georgia locations in collaboration with the GDPH and Children's Medical Services (CMS). The Valdosta and Albany clinics serve the largest number of children (Table 1 ) and therefore onsite clinics convene every two months (six per year). By contrast, clinics in Dublin and Waycross convene three times per year due to a smaller patient population (Table 1). 


\section{Services Provided During Telemedicine Clinics}

During clinics, vital signs, weight, height and pulse oximetry followed by a medical history are documented. The physical exam is conducted by the CMS nurse and a treatment plan is discussed by the hematologist via video conferencing. Laboratory tests including complete blood count and differential, reticulocyte count and chemical metabolic panel monitor HU therapy; for newborn screening confirmation of carrier states, a blood sample is sent to the Huisman Reference Laboratory at AU for high performance liquid chromatography and/or DNA analysis. Before leaving the clinic, patients or parents complete a survey on a voluntary basis to monitor satisfaction with services and quality improvement efforts.

\section{Telemedicine Survey}

The Institutional Review Board (IRB) at AU declared the survey data exempt non-human research. The surveys were de-identified and assigned an anonymous identification number. Survey questions include satisfaction with the length of time to get an appointment, length of time waiting in the office and the visual and voice quality of equipment. Additional items assessed satisfaction with time spent with the specialist, explanation of treatment by the specialist and how well the staff answered questions about the equipment. Finally, families rated courtesy, respect, sensitivity and friendliness of the specialist, how well the telehealth staff respected privacy, and overall treatment experience with telehealth. Possible answers for each question included poor, good, very good and excellent that converted to a numerical score of one (poor), two (good), three (very good), and four (excellent). Participants also responded to questions about whether they preferred telemedicine consultation or physician onsite visits. Lastly, patients were asked if they would use telehealth again or recommend to another person. Questions left blank were grouped in the "not answered" category.

\section{Statistical Analysis}

Descriptive statistics summarized the demographic and survey data by means and standard deviations. One-way ANOVA examined differences in patient response to satisfaction questions by telemedicine clinic location. Statistical significance was assessed at $\alpha=0.05$. All analyses performed using IBM SPSS Statistics for Windows, Version 25.0.

Table 3: Telemedicine surveys completed by clinic location.

\begin{tabular}{|c|c|c|c|c|c|}
\hline & & Outreach Clinic & & & \\
\hline & Albany & Dublin & Valdosta & Waycross & Total \\
\hline & $(N=35)$ & $(N=22)$ & $(N=21)$ & $(N=21)$ & $(\mathrm{N}=99)$ \\
\hline & N (\%) & N (\%) & $\mathrm{N}(\%)$ & N (\%) & $\mathrm{N}(\%)$ \\
\hline \multicolumn{6}{|l|}{ Sex } \\
\hline Male & $15(42.9)$ & $10(45.5)$ & $10(47.6)$ & $11(52.4)$ & $46(46.5)$ \\
\hline Female & $18(51.4)$ & $9(40.9)$ & $10(47.6)$ & $7(33.3)$ & $44(44.4)$ \\
\hline Not answered & $2(5.7)$ & $3(13.6)$ & $1(4.8)$ & $3(14.3)$ & $9(9.1)$ \\
\hline \multicolumn{6}{|c|}{ Used telemedicine before } \\
\hline Yes & $9(25.7)$ & $12(54.5)$ & $4(19.0)$ & $16(76.2)$ & 41 (41.4) \\
\hline
\end{tabular}

\section{Results and Observations}

\section{Pediatric Sickle Cell Program Demographics}

The AU Pediatric Sickle Cell Program provides services for over 700 children in five major locations (Table 1). The Children's Hospital of Georgia at AU serves 306 children; in South Georgia the number of children in each onsite outreach clinic are 201 children in Albany, 112 children in Valdosta, 50 in Dublin, and 40 in Waycross. The types of SCD in our population include $61.8 \%$ sickle cell anemia (HbSS and HbS $\beta 0$-Thalassemia), 21.7\% HbSC and 7.3\% $\mathrm{HbS} \beta+-$ Thalassemia. The population in the program is predominately African American (99.7\%), 54.7\% are male and within the children enrolled, $21.9 \%$ are using HU.

\section{Telemedicine Clinics Provide Increased Access To Subspecialty Care In Rural Communities}

Since the release of the National Heart Lung and Blood Institute (NHLBI) recommended standards of care, AU offers HU therapy to children at 9 months of age, to expand subspecialty follow-up, four telemedicine clinic sites were established in Valdosta, Albany, Dublin and Waycross, GA. Approximately 213 patients received services via telemedicine in South Georgia between February 2016 and November 2017 compared to 819 patient visits to onsite outreach clinics after referrals from local primary care providers. This time period was chosen to evaluate the effectiveness of our telemedicine program. The majority of visits were for HU follow-up $(61.5 \%)$ and confirmation of newborn screening findings of Bart's hemoglobin or sickle cell trait (23\%). The remaining visits were for other general hematology follow up (Table 2).

Table 2: Summary of telemedicine services delivered.

\begin{tabular}{|c|c|c|c|c|}
\hline \multirow{2}{*}{} & \multicolumn{4}{|c|}{ Clinic Location } \\
\cline { 2 - 5 } & Albany & Dublin & Valdosta & Waycross \\
\hline HU follow up & 17 & 45 & 29 & 40 \\
\hline $\begin{array}{c}\text { Newborn screening } \\
\text { follow up }\end{array}$ & 19 & 3 & 24 & 3 \\
\hline Other reason & 0 & 7 & 12 & 14 \\
\hline Total visits (\%) & $36(15.5)$ & $55(25.8)$ & $65(30.5)$ & $57(62.7)$ \\
\hline
\end{tabular}




\begin{tabular}{|c|c|c|c|c|c|}
\hline No & $21(60.0)$ & $7(31.8)$ & $15(71.4)$ & $5(23.8)$ & $48(48.5)$ \\
\hline Not answered & $5(14.3)$ & $3(13.6)$ & $2(9.5)$ & $0(0.0)$ & $10(10.1)$ \\
\hline
\end{tabular}

Since establishment of telemedicine, 213 out of 317 patients scheduled ( $67 \%$ show rate) received services across the four clinics. The CMS nurses at the four telemedicine sites collected survey data from 99 patients (46.75\%) immediately after clinic visits. Data distribution among the population included $46.5 \%$ male, $44.4 \%$ female and $<20$ years old; the majority of participants $(48.5 \%)$ were first time users of telemedicine services (Table 3 ).

\section{Telemedicine Services Rated Favorably By Families}

Table 4: Summary of family views of telemedicine experience by clinic.

\begin{tabular}{|c|c|c|c|c|c|c|}
\hline & \multicolumn{6}{|c|}{ Outreach Clinic } \\
\hline & Albany & Dublin & Valdosta & Waycross & Total & \multirow{2}{*}{ p-valuec } \\
\hline & $(\mathrm{N}=35)$ & $(\mathrm{N}=22)$ & $(\mathrm{N}=21)^{\mathrm{a}}$ & $(\mathrm{N}=21)$ & $(\mathrm{N}=99)^{\mathrm{b}}$ & \\
\hline 1. The length of time to get appointment & $3.57 \pm 0.56$ & $3.55 \pm 0.51$ & $3.90 \pm 0.30$ & $3.76 \pm 0.54$ & $3.68 \pm 0.54$ & 0.017 \\
\hline 2. The length of time waiting in the office & $3.63 \pm 0.49$ & $3.50 \pm 0.60$ & $3.95 \pm 0.22$ & $3.86 \pm 0.48$ & $3.72 \pm 0.50$ & 0.003 \\
\hline 3. The voice quality of the equipment & $3.74 \pm 0.44$ & $3.64 \pm 0.49$ & $3.95 \pm 0.22$ & $3.90 \pm 0.30$ & $3.80 \pm 0.40$ & 0.009 \\
\hline 4. The visual quality of the equipment & $3.80 \pm 0.41$ & $3.59 \pm 0.50$ & $3.90 \pm 0.30$ & $3.95 \pm 0.22$ & $3.81 \pm 0.40$ & 0.001 \\
\hline 5. The length of time with the specialist & $3.80 \pm 0.41$ & $3.59 \pm 0.50$ & $3.95 \pm 0.22$ & $3.90 \pm 0.30$ & $3.81 \pm 0.40$ & 0.006 \\
\hline 6.The explanation of time with the specialist & $3.86 \pm 0.36$ & $3.64 \pm 0.49$ & $3.95 \pm 0.22$ & $3.86 \pm 0.48$ & $3.83 \pm 0.41$ & 0.081 \\
\hline $\begin{array}{l}\text { 7. How well the staff here answered your questions about } \\
\text { the equipment }\end{array}$ & $3.77 \pm 0.43$ & $3.64 \pm 0.49$ & $3.95 \pm 0.22$ & $3.86 \pm 0.48$ & $3.80 \pm 0.48$ & 0.011 \\
\hline $\begin{array}{l}\text { 8. The courtesy, respect, sensitivity and friendliness of the } \\
\text { specialist you saw }\end{array}$ & $3.83 \pm 0.38$ & $3.73 \pm 0.46$ & $3.95 \pm 0.22$ & $3.90 \pm 0.30$ & $3.85 \pm 0.36$ & 0.126 \\
\hline 9. How well the telehealth staff respected your privacy & $3.80 \pm 0.41$ & $3.59 \pm 0.50$ & $3.95 \pm 0.22$ & $3.90 \pm 0.30$ & $3.81 \pm 0.40$ & 0.002 \\
\hline 10. Your overall treatment experience with telehealth & $3.82 \pm 0.39$ & $3.50 \pm 0.60$ & $3.95 \pm 0.22$ & $3.90 \pm 0.30$ & $3.79 \pm 0.43$ & $<0.001$ \\
\hline
\end{tabular}

Note: Items scored on a four-point scale ranging from poor to excellent, with higher scores indicating greater satisfaction levels.

aSample size $\mathrm{N}=20$ for items 6-10.

bample size $\mathrm{N}=98$ for items 6-10.

${ }^{c} \mathrm{p}$-values represent the ANOVA for between group differences in mean scores.

Telemedicine experiences of patients was overall positive for the ten survey items. The lowest scored item was "the length of time to get an appointment," which rated $3.68 \pm 0.54$ out of 4.0 points total and scores were highest in the Valdosta clinic (Table 4). The mean satisfaction scores varied significantly by outreach clinic on 8 out of 10 questions with the lowest scores occurring in Dublin and the highest in the Valdosta telemedicine clinic. Total mean scores ranged from $3.68 \pm 0.54$ to $3.85 \pm 0.36$ for all clinics during the evaluation period.

\section{Telemedicine Visit Preferred By A Significant Number of Families}

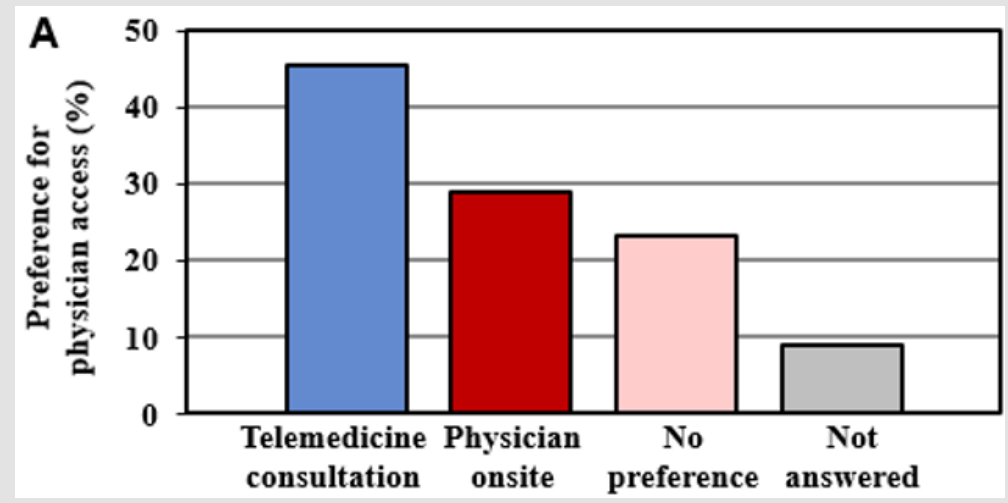

Figure 1A: Families responded whether they prefer a telemedicine consultation or physician onsite visits. Shown in the bar graph is preferences for access to subspecialty care. Some individuals did not answer the question (gray). 
To gain insights into preferences of families for medical services, a question was asked regarding preference for how medical services were delivered. We observed $45.5 \%$ preferred telemedicine care by telemedicine compared to $23.8 \%$ preferring to see the hematologist in onsite clinics (Figure 1A); of note, $22.5 \%$ of families indicated no preference. Overwhelmingly, $91.3 \%$ of patients reported they would use telemedicine again and would recommend telemedicine to another person (88.8\%) (Figures 1B \& 1C).

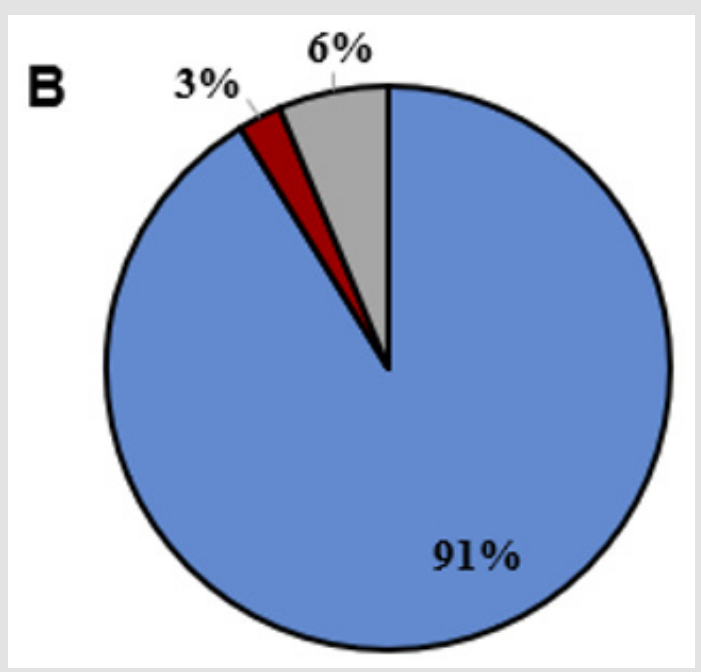

Figure 1B: Participants answered yes (blue) or no (red) to the questions whether they would use telemedicine again. Some individuals did not answer the question (gray).

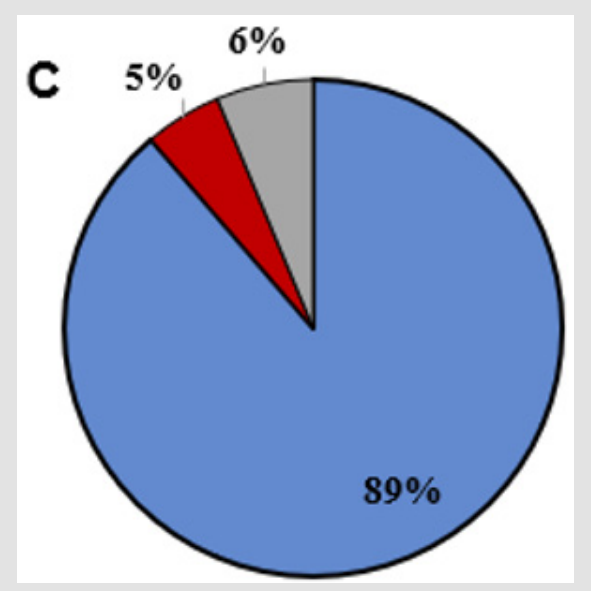

Figure 1C: Participants answered yes (blue) or no (red) to whether they would recommend telemedicine visits to others. We observed 6-9\% of families did not answer these three questions.

\section{Discussion}

The majority of families reported a positive experience with telehealth technology or had no preference for onsite clinics as first time users of this service. The shorter wait times and length of time spent with the hematologist rated highly. In general, longer wait times were experienced in onsite clinics due to the large number of patients scheduled per clinic. The results suggest that although some families prefer a physician onsite visit, the majority would use telemedicine again and recommend to another person. Consistently, surveys rated highest in Valdosta, GA and may reflect the longest experience and the same CMS nurse for both onsite and telemedicine clinics.

When establishing the telemedicine program at $\mathrm{AU}$, one concern was clinic acceptance of services via video conferencing and potential for low attendance. However, show rates for telemedicine and onsite clinic visits were comparable. Also, access to care increased by $50-75 \%$ based on the number of hematology onsite clinics offered without increasing the travel time required to conduct additional clinics in South Georgia. Telemedicine clinics increased our ability to initiate and monitor safety of HU therapy; however, additional physician clinical effort was required.

One survey item related to the length of time required to schedule an appointment for telemedicine consultation. Our findings suggest monthly access for hematology services through either onsite or telemedicine clinics are not meeting the needs of patients in South GA, but limited faculty prohibited expanding services further. To meet this need will require greater funding for CMS nurses, physician time and a dedicated telemedicine coordinator to schedule and operate additional clinics.

Additional studies have shown a positive impact on patient's experiences supporting the use of telemedicine for medical care to monitor complex diseases [3-12]. The rapid increase in telemedicine technology has been successful for the management of acute infectious diseases, human immunodeficiency virus, chronic hepatitis $\mathrm{C}$ and active pulmonary tuberculosis in rural populations [13]. As in other specialty areas, there is a shortage of infectious disease physicians particularly in rural areas and smaller hospitals [14]. In 2019, the Infectious Disease Society of America endorsed the use of telehealth clinics as a way to embrace change in the way healthcare is delivered and also for medical education $[14,15]$. In a study conducted by Young, et al., telemedicine clinics conducted by specialists were used in a correctional population to manage human immunodeficiency virus and resulted in significantly greater viral suppression and higher CD4 T-lymphocytes counts [16]. Telehealth programs have also improved viral suppression in human immunodeficiency virus clinics among several Veterans Affairs health programs in the United States [17]. Moreover, telehealth technology has been used as a tool for implementing antimicrobial stewardship programs in consultation with pediatric physicians to improve antibiotic usage and subsequently reducing cost and decreasing the incidence of multidrug-resistant organisms and infections $[18,19]$.

\section{Study Limitations}

Since our patient population was under age 21 years, parents and/or caregivers provided feedback and it is unclear if these outcomes would differ in an adult population. There was no selection 
bias for participants receiving telemedicine services because they were enrolled in the SCD program and volunteered to participate in the survey after clinic visits were completed. Variability in patient size and longer experience of the CMS nurses at the different outreach clinic sites may have influenced telemedicine experience. Since the study assessed patient satisfaction with telemedicine, it is possible to use the survey questions in a variety of settings when assessing programs.

\section{Conclusion}

Overall, patients reported positive experiences with telehealth technology, staff and hematologists and rated care received by telemedicine services favorable. Healthcare providers are adopting telemedicine to increase healthcare access and improve patient outcomes. Barriers of access to care for patients with specialized healthcare needs are addressed by telemedicine. Future studies to better understand the cost effectiveness and economic impact of utilizing telemedicine are needed.

\section{Acknowledgement}

We would like to thank Mrs. Judi Schweitzer for her leadership in coordinating the telemedicine clinics in collaboration with dedicated CMS nurses in the Valdosta, Dublin, Waycross and Albany, GA health departments that conduct telemedicine and onsite outreach clinics. We thank other members of the Pediatric Sickle Cell Program staff including Ms. Cynthia Williams, Newborn Screening Nurse and Ms. Ann Sapp, Office Associate for support of the program.

\section{References}

1. Singh R, Jordan R, Hanlon C (2014) Economic impact of sickle cell hospitalization. Blood 124(21): 5971.

2. (2014) Lung NH, Institute B. Evidence-based management of sickle cell disease. Expert Panel report Washington, DC: National Institutes of Health.

3. Marcin JP, Shaikh U, Steinhorn RH (2016) Addressing health disparities in rural communities using telehealth. Pediatr res 79(1-2): 169-176.

4. Woods KF, Kutlar A, Johnson JA, Waller JL, Grigsby RK, et al. (1999) Sickle cell telemedicine and standard clinical encounters: A comparison of patient satisfaction. Telemedicine J 5(4): 349-356.

5. Woods KF, Johnson JA, Kutlar A, Daitch L, Stachura ME (2000) Sickle cell disease telemedicine network for rural outreach. J Telemed telecare 6(5): 285-290.

ISSN: 2574-1241

DOI: 10.26717/BJSTR.2019.22.003697

Betty S Pace. Biomed J Sci \& Tech Res

This work is licensed under Creative

Commons Attribution 4.0 License

Submission Link: https://biomedres.us/submit-manuscript.php
6. Woods K, Kutlar A, Grigsby RK, Adams L, Stachura ME (1998) Primarycare delivery for sickle cell patients in rural Georgia using telemedicine. Telemed J 4(4): 353-361.

7. Chonat S, Quinn CT (2017) Current standards of care and long-term outcomes for thalassemia and sickle cell disease. Adv Exp Med Biol 1013: 59-87.

8. Gaston MH, Verter JI, Woods G, Pegelow C, Kelleher J, et al. (1986) Prophylaxis with oral penicillin in children with sickle cell anemia. A randomized trial. N Engl J Med 314(25): 1593-1599.

9. Charache S, Terrin ML, Moore RD, Dover GJ, Barton FB, et al. (1995) Effect of hydroxyurea on the frequency of painful crises in sickle cell anemia. Investigators of the Multicenter Study of Hydroxyurea in Sickle Cell Anemia. N Engl J Med 332(20): 1317-1322.

10. Wang WC, Ware RE, Miller ST, Iyer RV, Casella JF, et al. (2011) Hydroxycarbamide in very young children with sickle-cell anaemia: A multicentre, randomised, controlled trial (BABY HUG). Lancet 377(9778): 1663-1672.

11. Crosby LE, Barach I, McGrady ME, Kalinyak KA, Eastin AR, et al. (2012) Integrating interactive web-based technology to assess adherence and clinical outcomes in pediatric sickle cell disease. Anemia 2012: 492428.

12. Olson CA, Thomas JF (2017) Telehealth: No Longer an Idea for the Future. Adv Pediatr 64(1): 347-370.

13. Parmar P, Mackie D, Varghese S, Cooper C (2015) Use of telemedicine technologies in the management of infectious diseases: A review. Clin Infect Dis 60(7): 1084-1094.

14. Abdel-Massih RC, Mellors JW (2019) Telemedicine and infectious diseases practice: A leap forward or a step back? Open Forum Infect Dis 6(5).

15. Siddiqui J, Herchline T, Kahlon S, Moyer KJ, Scott JD, et al. (2017) Infectious disease society of America position statement on teleheatlh and telemedicine as applied to the practice of infectious diseases. Clin Infect Dis 64: 237-242.

16. Young J, Patel M, Badowski M, Mackesy-Amiti ME, Vaughn $P$, et al. (2014) Improved virologic suppression with HIV subspecialty care in a large prison system using telemedicine: An observational study with historical controls. Clin infect Dis 59(1): 123-126.

17. Ohl ME, Richardson K, Rodriguez-Barradas MC, Bedimo R, Marconi V, et al. (2019) Impact of availability of telehealth programs on documented HIV viral suppression: A cluster-randomized program evaluation in Veterans Health Administration. Open Forum Infect Dis 6(6).

18. Ceradini J, Tozzi Ae, D”Argenio P, Bernaschi P, Manuri L, et al. (2017) Telemedicine as an effective intervention to improve antibiotic appropriateness prescription and to reduce costs in pediatrics. Ital J Pediatr 43(1): 105.

19. Santos D, Dalmora CH, Lukasewicz SA, Carvalho O, Deutschendorf C, et al. (2019) Antimicrobial stewardship through telemedicine and its impact on multi-drug resistance. J Telemed Telecare 25(5): 294-300.

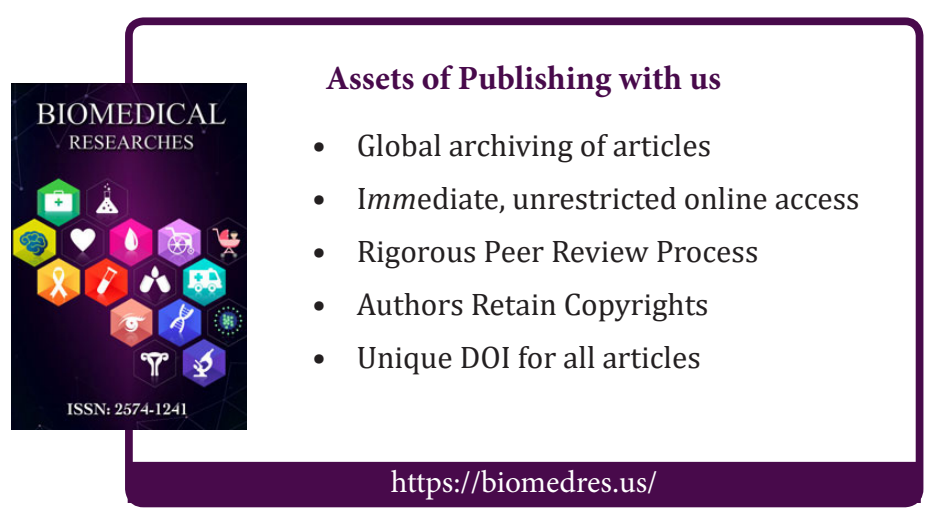

